NBER WORKING PAPER SERIES

\begin{abstract}
ALTERNATIVE AND PART-TIME EMPLOYMENT ARRANGEMENTS AS A RESPONSE TO JOB LOSS
\end{abstract}

Henry S. Farber

Working Paper 7002

http://www.nber.org/papers/w7002

\author{
NATIONAL BUREAU OF ECONOMIC RESEARCH \\ 1050 Massachusetts Avenue \\ Cambridge, MA 02138 \\ March 1999
}

The views expressed in this paper are those of the authors and do not reflect those of the National Bureau of Economic Research.

1999 by Henry S. Farber. All rights reserved. Short sections of text, not to exceed two paragraphs, may be quoted without explicit permission provided that full credit, including ${ }^{\circledR}$ notice, is given to the source. 
Alternative and Part-Time Employment

Arrangements as a Response to Job Loss

Henry S. Farber

NBER Working Paper No. 7002

March 1999

JEL No. J30

\begin{abstract}
I examine the extent to which workers who lose jobs find work in alternative employment arrangements including temporary work and independent contracting and find part-time work, both voluntary and involuntary. The analysis is based on data from the Displaced Worker Supplements (DWS) and the February 1994 and 1996 Current Population Surveys (CPS) which I match to the Contingent and Alternative Employment Arrangements Supplements (CAEAS) to the February CPSs in the subsequent years (1995 and 1997 respectively). I find that job losers are significantly more likely than non-losers to be in temporary jobs (including on-call work and contract work). I also find evidence that the likelihood of temporary employment falls with time since job loss. With regard to part-time employment, I find that involuntary part-time employment is an important part of the employment experience subsequent to job loss and that the likelihood of involuntary part-time employment falls with time since job loss, particularly for full-time job losers. Thus, it appears that temporary and involuntary part-time jobs are part of a transitional process subsequent to job loss leading to regular full-time employment.
\end{abstract}

\author{
Henry S. Farber \\ Industrial Relations Section \\ Firestone Library \\ Princeton University \\ Princeton, NJ 08544 \\ and NBER \\ farber@princeton.edu
}




\title{
Alternative and Part-Time Employment Arrangements as a Response to Job Loss
}

\author{
Henry S. Farber
}

\section{Introduction}

The purpose of this study is to examine the extent to which workers who lose jobs find work in alternative employment arrangements, including temporary work and independent contracting and in voluntary or involuntary part-time jobs rather than as conventional fulltime employees. My analysis is based on data from the Displaced Worker Supplements (DWS) to the February 1994 and 1996 Current Population Surveys (CPS) which I match to the Contingent and Alternative Employment Arrangements Supplements (CAEAS) to the February CPSs in the subsequent years (1995 and 1997 respectively). These data allow me to identify job losers in the DWS, and they contain detailed information on their post-displacement employment arrangements from the CAEAS.

Interest in this subject is motivated by several factors. First, while employment in the United States has grown steadily for the last twenty years, substantial concern exists about the quality of the stock of jobs. ${ }^{1}$ Areas of concern include increased inequality in wages, a decline in real wages at the lower end of the distribution, and reductions in important fringe benefits such as employer-provided health insurance. ${ }^{2}$ Second, concern has developed in the last decade regarding high rates of job loss and reduced job security. ${ }^{3}$

Support for this research was provided by the Office of the Assistant Secretary of Labor for Policy, United States Department of Labor under Purchase Order No. B9462164 and by the Industrial Relations Section at Princeton University. Karen Conneely and Harry Krashinsky provided able research assistance. Susan Houseman and David Neumark and two anonymous referees provided useful comments on earlier drafts.

1 Civilian employment was 89.9 million in January 1977 and rose to 128.6 million in January 1997, for an average annual increase of almost 2 million jobs per year. These statistics are taken from U.S. Bureau of Labor Statistics Series ID LFS11000000. This is the Seasonally adjusted civilian employment level derived from the Current Population Survey for workers aged 16 and older.

2 See Farber (1997c) for a brief review of and references to the literature on job quality and for an analysis of the quality of new jobs. Farber and Levy (1998) present an analysis of the decline in employer-provided health insurance that focuses on workers in new jobs and on part-time workers.

3 The most recently available data show elevated rates of job loss in the 1993-1995 period (Farber, 
Finally, there has been concern about an increase in the fraction of the work-force in parttime and temporary jobs. ${ }^{4}$ The evidence also suggests that these jobs do not offer pay, fringe benefits, or opportunity for advancement comparable to those on regular jobs. ${ }^{5}$

The interaction between job loss and alternative work arrangements has not been examined in previous work. In my earlier work (Farber, 1997a) I found that workers who lose jobs are more likely to be reemployed in part-time jobs and, even when reemployed in a full-time job, they earn significantly less than they did prior to their job loss. Part of these costs associated with job loss may be related to difficulty finding conventional employment arrangements. The central goal of this study is to provide statistical evidence on the extent to which alternative employment arrangements are, in fact, a common response to job loss. I find that temporary employment and involuntary part-time employment are used disprortionately by job losers, and I also investigate in some detail whether or not these alternative employment arrangements are a transitional experience for job losers.

\section{The February 1995 and February 1997 CAEAS Data}

The February 1995 and 1997 Contingent and Alternative Employment Arrangements supplements to the CPS contain information on alternative employment arrangements held at the survey date. Workers in alternative employment arrangements include independent contractors, consultants, free-lance workers, other self-employed workers, temporary workers, on-call workers, and contract workers. In order to focus the analysis, I combine these into three categories. The first, which I call independent contractors, consists of independent contractors, consultants, and free-lance workers. The second is composed of other

1997a) and a reduction between 1993 and 1996 in the fraction of the workforce who have been in their jobs for long periods of time (Farber, 1997b). For further analyses of job loss and its consequences see Farber (1993), Gardner (1995), Kletzer (1989), Neal (1995), Parent (1995) Podgursky and Swaim (1987), and Topel (1990)

4 See, for example, Abraham (1990), Abraham and Taylor (1996), Belous (1989), Blank (1990b), Golden and Applebaum (1992), Houseman (1997), and Howe (1986) for discussions of the incidence of and motivations for alternative employment arrangements.

5 See, for example, Blank (1989, 1990a), Ferber and Waldfogel (1996), Montgomery and Cosgrove (1993), and Tilly (1991). 
self-employed workers (other-SE). The third, which I call temporary workers, consists of temporary, on-call, and contract workers. ${ }^{6}$

In order to place workers in these categories, I use data from the basic CPS questionnaire as well as from the CAEAS. Specifically, a worker is classified as an independent contractor if he/she is employed at the survey date, is classified as self-employed in the basic CPS, and responds affirmatively in the CAEAS that he/she is ". . . self-employed as an independent contractor, independent consultant, free-lance worker, or something else." A worker is classified as other-SE if he/she is employed at the survey date, is classified as self-employed in the basic CPS, and is not classified as an independent contractor as defined here. ${ }^{7}$ A worker is classified as a temporary worker if he/she is employed at the survey date, is not classified as either type of self-employed worker, and responds affirmatively that he/she is in a temporary job, works for a temporary work agency, is an on-call worker, is a day laborer, or is a contract employee. All other workers (including part-time) are classified as "regular" workers.

\section{The Incidence of Alternative Employment Arrangements}

The first four columns of table 1 contain weighted breakdowns of employment arrangements for 102,318 individuals in the February 1995 and 1997 CAEASs aged 20-66 who are employed at the survey date. ${ }^{8}$ The first row of the table contains the breakdown for the

\footnotetext{
6 Another potential way to identify temporary workers is to classify those workers who report their industry of employment as personnel supply services (Census Industry Code 731). However, most workers who actually work for personnel supply firms apparently report themselves as employed in the industry to which they are assigned. Evidence for this is that the Current Employment Survey data, which are based on information collected from employers, shows that 2.2 percent of nonfarm employment was in the personnel supply services industry (SIC 736) in 1997 (based on BLS series EEU00000001 and EEU8073601). In contrast, my tabulations the February 1997 CPS shows that 0.76 percent of employment was in the personnel supply services industry (CIC 731). Additionally, the personnel supply services industry includes an unknown number of workers who are not temporary workers. Thus, use of this industry classification to identify temporary workers in the CPS is not likely to be very useful here. See Segal and Sullivan (1997) for an analysis that does use this method to identify temporary workers. See also Polivka (1996).

7 Many of these workers are likely to be owners of small businesses.

8 This age range was selected to match individuals who were 20-64 in the February 1994 DWS. These percentages and other statistics presented in this study are weighted by the CPS final sampling weights. The CAEAS is distributed with special supplement weights to account for non-response to the supplement. These are based on differential response rates by demographic group, and they are highly correlated with the final sampling weights (correlation $=0.9988$ ). Thus, while my use of the final sampling weights would understate overall population counts relative to those derived by using the special supplement weights,
} 
entire sample, and it shows 82.5 percent in "regular" employment relationships, 5.9 percent independent contractors, 5.4 percent other-SE, and 6.2 percent temporary workers.

The last three columns of table table 1 contain weighted breakdowns of full/parttime status for the same sample. The full/part-time distinction is made using data from the basic CPS information on hours of work. Part-time workers are those whose total hours on all jobs are less than 35 hours per week. ${ }^{9}$ Those part-time workers who report a preference for working full-time and who report being part-time for economic reasons (slack work, can't find a full-time job, seasonal work) are classified as involuntary part-time. The remainder are classified as voluntary part-time. The first row of the table contains the breakdown for the entire sample, and shows 84.7 percent in full-time employment relationships, 10.8 percent voluntarily part-time, and 4.5 percent involuntarily part-time.

The remainder of table 1 contains breakdowns of employed workers by type of employment and full/part-time status separately by sex, education level, and age. ${ }^{10}$ A significantly larger fraction of females than males (85.1 percent vs. 80.2 percent) are in regular employment relationships. This is due to the fact that females are significantly less likely than males (8.5 percent vs. 13.8 percent) to be self-employed (either type). There is only a small difference by sex in the rate of temporary employment. Despite being more likely to be in regular employment arrangements, females are substantially more likely than males to be employed part-time. The overall differential of 15.3 percentage points is accounted for largely by a 13.5 percentage point differential in the rate of voluntary parttime employment which is supplemented by a 1.9 percentage point differential in the rate of involuntary part-time employment. These differences likely reflect systematic differences in labor supply between men and women.

both weights will yield similar results with regard to computation of means and proportions.

9 The algorithm for assigning part-time status to workers has several steps: 1) a worker is considered part time if usual total hours are less than 35 per week; 2) where usual total hours are missing then a worker is considered full time if usual hours on the main job are at least 35 per week; 3 ) where part-time status remains unassigned actual total hours during the reference week are used; and, finally, 4) an indicator in the basic CPS for "usually full time" is used to resolve the remaining cases.

10 While not presented here, I also carried out multivariate probit analyses of the probability of being in employment relationships of each type. These probit models controlled for race as well as for sex, and education, and age, and they show the same relationships of the likelihood of alternative arrangements as the simple breakdowns in table 1 . 
There is not a strictly monotonic relationship between education category and the incidence of regular employment relationships, but the most obvious pattern is that workers with at least 16 years of education have lower rates of regular employment (about 2 to 4 percentage points lower) than do workers with less education. This is accounted for by higher rates of self-employment (both types) among workers in the highest education category. With respect to part-time employment, the most striking difference is that workers in the highest education category have substantially higher full-time employment rates than do workers with less education. Workers with 12 years of education have an intermediate rate of full-time employment. The fact that the involuntary part-time rate is monotonically declining with education accounts for these findings (along with the unusually high voluntary part-time rate for workers with 13-15 years of education).

The fraction of workers in regular employment relationships declines monotonically with age. This results from an increase with age in the proportion of workers who are self-employed (both types) and a decrease with age in the fraction of workers who are in temporary jobs. The temporary job rate is particularly high for workers in the youngest age category. Full-time employment rates are lowest for workers in the youngest and oldest age categories, and this is primarily due to high voluntary part-time rates among workers in these two age categories. For the youngest workers, this may reflect part-time work while in enrolled in school. For the oldest workers this may reflect decreased labor supply of workers approaching retirement.

Note that the type of employment arrangements and full/part-time status are not independent. Table 2 contains a cross-tabulation of employment arrangements with part-time status for the 102,318 workers in the combined February 1995 - February 1997 sample used in table 1.11 Regular workers are substantially more likely to be full time and less likely to be in either part-time category than are workers in the other employment arrangements. On the other extreme, temporary workers are least likely to be full time and most likely to be in either part-time category. Fully 24.4 percent of temporary workers are voluntarily part-time and 11.9 percent of temporary workers are involuntarily part-time.

11 A Pearson chi-squared text of independence in table 2 yields a test statistic of 3586.5 distributed as $\chi^{2}(6)$ and clearly rejects independence $(p$-value $<0.000001)$. 
This compares with 9.2 percent of regular workers in voluntary part-time jobs and 3.4 percent of regular workers in involuntary part-time jobs. The self-employed categories are intermediate in their full/part-time status.

\section{Matching the February DWS and February CAEAS Data}

The first step in matching the February 1994 and 1996 DWSs with the February 1995 and 1997 CAEASs respectively is to define the pool of individuals eligible to be matched from the DWSs. In order to be eligible to be in the CPS in both the DWS and CAEAS in the subsequent year, a household must be in one of its first four months in the sample in the DWS. Such a household is then eligible to be in the sample in the CAEAS in the subsequent year (in one of its four months back in the sample after an eight-month hiatus). But, because addresses rather than specific households or individuals are sampled and surveyed, only individuals who have not moved in the intervening year are eligible to be matched. Information contained in the CPS since 1994 is meant to allow an exact match of individuals across CPSs, but, in order to reduce the likelihood of coding errors leading to inappropriate matches, I also match on a set of demographic characteristics (age, sex, and race).

I restrict my analysis to individuals aged 20-64 in the Februarys with the DWSs (1994 and 1996). There are 39,841 individuals in this age group in rotation groups 1-4 in February 1994 and there are 34,689 individuals in this age group in rotation groups 1-4 in February 1996. Thus, 74,530 individuals are eligible to be matched with individuals in the CAEAS in the subsequent year (February 1995 or February 1997). Of these, I am able to match 50,620 for a match rate of 67.9 percent. A problem is that the match rate depends centrally on whether or not individuals have changed residence between the survey dates. Not surprisingly, workers who lose jobs (defined precisely later in this section) are more likely to change residence. The match rate among job losers is 65.4 percent compared with a 69.1 percent match rate among non-losers. The lower match rate among job losers is particularly unfortunate given the focus of this study, but there is no obvious solution to this problem. 
It might be expected that the distribution of type of employment in the CAEAS in the subsequent year would be related to the probability of matching, with those in alternative employment relationships less likely to be matched. It turns out that there are generally small differences in the distributions of employment arrangements by whether the observation was matched. Specifically, recall that 82.5 percent of the overall sample from the CAEAS (including all 8 rotation groups) were employed in regular jobs. Among those matched, 82.9 percent were employed in regular jobs. The comparisons for the other categories are fairly close: independent contractors (5.9 percent overall vs. 5.6 percent matched), other self-employed (5.4 percent overall vs. 6.8 percent matched), and temporary (6.2 percent overall vs. 4.7 percent matched). It appears that other self-employed are more likely to be matched, and this may reflect the fact that, based on the algorithm that defines this category, independent business owners are included in this category and these businesses are not likely be geographically mobile. On the other hand, temporary workers are less likely to be matched. While there is nothing that can be done about this problem, it is important to note these differences in match rates.

\section{Job Loss as Defined by the Displaced Worker Survey}

The February 1994 and 1996 DWSs ask workers if they were displaced from a job at any time in the preceding three-year period (1991-93 and 1994-1996 respectively). Other events including quits and being fired for cause are not considered displacement. Thus, the supplement is designed to focus on the loss of specific jobs that result from business decisions of firms unrelated to the performance of particular workers.

The central use of the DWS for the purposes of this study is to identify individuals who have lost a job in the relevant intervals. While job loss as measured by the DWS almost certainly does not represent all job loss about which we ought to be concerned, it does represent the best available source of data on job loss. ${ }^{12}$ Overall, 6,637 individuals aged 20-64 reported in the February 1994 DWS having lost a job in the 1991-93 period. Similarly, 6,459 individuals aged 20-64 reported in the February 1996 DWS having lost a

12 See Farber (1997a) for a detailed discussion of the definition and limitations of the measure of job loss from the DWS. 
job in the 1994-96 period. ${ }^{13}$ Of these 13,096 job losers, 6,733 were in rotation groups 1-4, and, hence, are potentially matchable to the subsequent CPSs with the CAEAS.

\section{The Final Match}

Of the 50,620 individuals aged 20-64 in the February 1994 and 1996 CPSs who were successfully matched to the February 1995 and 1997 CPSs, 2,145 were not interviewed for the displaced worker supplement so that there is no information on job loss for these workers. These individuals are dropped from the analysis. While only the employed were eligible to be interviewed for the CAEAS, I am interested in all employment-related outcomes for displaced workers. Thus, for now I retain those who are not employed at the CAEAS date. But 3,412 employed individuals were not administered the CAEAS. When these non-respondents are eliminated from the sample, there are 45,063 individuals including 4,102 job losers left in the matched sample, and they form the core of the analysis using the matched data. There is complete information for this sample on job loss in the three-year period prior to the DWS and on employment arrangements in the subsequent CAEAS. Of the 45,063 individuals in the sample, 33,296 are employed at the relevant CAEAS date.

\section{Job Loss and Alternative Employment Arrangements: The Matched Data}

Table 3 contains a breakdown of employment arrangements at the CAEAS date by whether the individual reported a job loss in the three years prior to the relevant DWS. The sample contains all individuals, whether employed at the CAEAS date or not. In particular, it shows the fraction of the sample separately for job losers and non-losers that are in each type of employment (or non-employment) arrangement. I also present the difference between the rates for non-losers and the rates for losers, and I call this difference the job-loss differential.

These data include individuals who are not employed in order to highlight two issues. First, individuals who lost jobs in the three years prior to the DWS are more likely than

13 These represent 8.6 and 10.6 percent (weighted) of the total samples respectively. However, these are not good estimates of the job-loss rates because many of those sampled had not worked and, hence, were not at risk to lose a job. 
non-losers (6.2 percentage points) to report being unemployed a year after the DWS date. ${ }^{14}$ Second, job losers are less likely than non-losers (6.8 percentage points) to be out of the labor force (NILF) a year after the DWS date. This is because in order to have lost a job, workers must have been employed at some point in the three years prior to the DWS. Many of the workers who were not job losers have been out of the labor force for a long period of time (or never in the labor force).

It would be most appropriate to omit workers with no long-term attachment to the labor force from the analysis because they are not (to a first approximation) affected by job loss, but it is not possible to identify these workers. I proceed by analyzing employment status of the sample of workers who are employed at the CAEAS date. Since a substantial fraction of job losers are not employed (25.6 percent in table 3), this analysis errs in excluding individuals who were affected by job loss. Nonetheless, it gives the clearest picture of the distribution of employment arrangements subsequent to job loss and how this distribution is related to a history of job loss.

Table 4 is organized identically to table 3 with the difference that the breakdown in table 4 recomputes the fraction of workers in each type of employment relationship excluding those who are not employed. The results show that employed job losers have a smaller probability than non-losers of being in a regular job. The job-loss differential for temporary work is positive, suggesting that job losers who find work are substantially more likely than non-losers to be in temporary jobs (by 5.7 percentage points). Another difference is that job-losers are less likely to be other-SE (by 3.1 percentage points), but there is not a significant job-loss differential in the probability of being an independent contractor. The analysis in table 3, which includes those not employed, yields the same qualitative results.

A word is required on the interpretation of the two self-employed categories. The "independent contractor" category includes self-employed workers who say that they are independent contractors, independent consultants, free-lance workers, or something else. This appears to be the category that captures the sort of self-employment arrangements

14 Higher unemployment rates among displaced workers is well known from the literature on job displacement. See, for example, Podgursky and Swaim (1987). 
individuals might find themselves after leaving a company and 1) perhaps performing the same function for their old employer on a contract basis or 2) starting a "consulting" business selling their services. The "other self-employed" category is the residual and likely captures owners of small business (e.g., retail sales). As such, the "contractor" category is more likely to be used by job losers than the "other-SE". This is consistent with the tabulations in tables 3 and 4 .

The next step is to carry out multivariate analyses of the probability of employment by type in order to estimate the job-loss differentials in employment probabilities controlling for demographic characteristics. Given the similarity of the relationship between job loss and type of employment found in the analysis that includes those not employed and the analysis that focuses on those employed, I continue using only the sample composed of those employed at the CAEAS survey date. I estimate simple probit models of the probability of employment of the various types as a function of job-loss status, age, education, sex, marital status, the interaction of sex and marital status, and race. ${ }^{15}$

The key variable for the purposes of this study is the job loss indicator. Its normalized coefficient measures the adjusted (for demographic characteristics) lost-job differential in the probability of employment of the indicated type controlling for the observable demographic characteristics. ${ }^{16}$ The differences in the structure of employment relationships across demographic groups implicit in the probit estimates are as noted in the raw tabulations in table 1 from the February 1995 and 1997 CAEASs, and, for this reason, the estimates of the coefficients of the demographic variables are not presented here.

The first row of table 5 contains the adjusted job-loss differentials for the overall sample of 33,095 workers. The results are similar to the unadjusted differences found in table 4 .

15 Note, that I am not estimating a multinomial choice model of employment type, such as multinomial logit or probit. What I am interested in here is data description and summary rather than estimates of some structural choice model. The ease of interpretation of the estimates from the binomial probit models make them a preferred method for this purpose.

16 The coefficients are normalized to represent the derivative of the probability of the outcome with respect to a change in the particular explanatory variable evaluated at the means of the explanatory variables. The normalization factor is $\phi(\bar{X} \hat{\beta})$ so that the normalized coefficient is computed as $\hat{\beta} \phi(\bar{X} \hat{\beta})$ where $\hat{\beta}$ is the vector of estimated parameters of the probit model, $\vec{X}$ is the vector of means of the explanatory variables, and $\phi$ is the standard normal probability density function. The standard errors are also normalized by $\phi(\bar{X} \hat{\beta})$, but they do not take into account the fact that the normalization itself is a random variable. 
Job losers are about 2.8 percentage points less likely than non-losers to be in regular jobs. There is no difference by job-loss status in the probability of being an independent contractor, but job losers are significantly less likely than non-losers to be in other-SE jobs (3.1 percentage points). Job losers are significantly more likely to be in temporary jobs (4.1 percentage points).

The job-loss differentials in the first row of table 5 control for observable differences across workers, but they constrain the job-loss differential in the employment outcomes to be the same for all types of workers. I relax this restriction by estimating separate probit models for various categories of workers. Each of these probit models contain the same set of variables as the overall model (omitting the set of variables on which the particular subsample is stratified). The remaining rows of table 5 contain the normalized probit coefficients of the job-loss dummy variable from each of these models for 1) separate models by sex and marital status, 2) separate models by educational category, and 3) separate models by age category.

The adjusted job-loss differentials estimated from separate probit models by sex and marital status are not very different. The adjusted job-loss differentials show lower probabilities of regular employment and other-SE for job losers, and these differentials are largest for unmarried workers of both sexes. This is offset largely by higher probabilities of temporary work for job losers. Single females who lose jobs also show a higher probability of being an independent contractor.

The adjusted job-loss differentials estimated from separate probit models by educational category suggest that there is a contrast in the job-loss differentials between workers with less than 16 years of education and workers with 16 or more years of education. While job losers with less than 16 years of education are about 1 percentage point less likely than non-losers to be employed in a regular job, job losers with at least 16 years of education are fully 6 percentage points less likely than non-losers to be employed in regular jobs. This difference across education groups appears to be accounted for largely by 1) a higher adjusted job-loss differential in the probability of being an independent contractor (about 1.8 percentage points for highly educated workers compared with zero for less educated workers), and 2) a higher adjusted job-loss differential in the probability of being a temporary 
worker (about 5.1 percentage points for highly educated workers compared with about 3.5 to 4 percentage points for less educated workers). Job losers in all educational categores are about three percentage points less likely than non-losers to be other self-employed,

The remainder of table 5 contains the adjusted job-loss differentials estimated from separate probit models by age category. It appears that the largest job-loss differential in the probability of regular employment is largest for middle-aged workers (35 to 54 years of age). The positive job-loss differential in the rate of temporary employment is shared by workers in all age categories but the youngest. The negative relationship between job loss and the rate of other-SE is stronger among older workers.

To summarize, employed job losers are more likely to be in alternative employment arrangements, broadly defined, than are non-losers. The largest consistent differences are that job losers are more likely than non-losers to be in temporary jobs and job losers are less likely than non-losers to be "other self-employed" workers. There is also some evidence that highly educated job-losers are more likely to be independent contractors relative to similarly educated non-losers.

\section{Is Temporary Employment Subsequent to Job Loss a Transitional Experience?}

There are at least two interpretations of the finding that workers who have lost jobs are more likely to be in temporary jobs. The first is that temporary employment relationships are used by some workers in a transition period following job loss due to difficulty in finding regular employment. Following this transition period, displaced workers will find regular employment. The second interpretation is that the relationships between job loss and temporary employment are the result of unmeasured heterogeneity across workers so that workers who tend to be employed in temporary jobs are also workers who are more likely to lose jobs regardless of the type of job they are holding.

While the data do not allow me to make a definitive determination of the relative importance of these two explanations, there is some evidence available that can shed some light on this issue. The first explanation (alternative employment as a transition phase) implies that the probability that a worker holds a temporary job will decline with time since displacement. The second explanation (unmeasured heterogeneity) has no such implication. 
I investigate this directly using the matched sample and information available in the DWSs reporting the year of job loss. Unfortunately, the design of the 1994 and 1996 DWSs was such that the year of job loss was asked only of individuals who reported losing a job for a subset of the allowed reasons. Specifically, individuals who reported losing a job due to 1) a plant closing, 2) slack work, or 3) position or shift abolished were asked follow-up questions including the year of job loss. Individuals who reported losing a job for other reasons were not asked the follow-up questions. Thus, information on the year of job loss is available for only 2056 of the 3031 workers who reported a job loss in February 1994 or 1996, were matched to an observation in February 1995 or 1997, and who were employed at the survey date in February 1995 or 1997. I computed the number of years since job loss for these 2056 workers. Given that job loss occurred in the three years prior to the DWS date, years since job loss ranges from 2 to 4 years at the CAEAS date. Of the 2056 workers in the sample, 851 reported a loss two years earlier, 612 reported a loss three years earlier, and 593 reported a loss four years earlier. ${ }^{17}$

Table 6 contains a breakdown of employment arrangements by years since job loss, and it confirms that the likelihood of regular employment increases with time since job loss (by 3.4 percentage points from 2 to 4 years, p-value $=0.043)$ ). In fact, at four years since job loss (three years prior to the DWS date, four years prior to the CAEAS date), the fraction of losers employed in regular jobs is virtually identical to the fraction of non-losers in regular jobs. This can be accounted for by a decline in the likelihood of temporary employment with time since job loss (by 4 percentage points from 2 to 4 years, $\mathrm{p}$-value $=0.00023$ ), although the likelihood of temporary employment among job losers still substantially exceeds the likelihood of temporary employment among non-losers, even after four years. There are also offsetting movements with time since job loss in the likelihood of being in the two self-employment categories. However, these movements are not statistically significant at conventional levels. The movements with time since job loss

17 I have repeated the analyses of adjusted job-loss differentials using only non-losers and this restricted sample of job losers, and the results are very similar. The declining number of job losers with time since the survey likely reflects recall bias. Such bias makes it more likely that recent events and more salient events are recalled. (Topel, 1990) 
in the likelihood of regular and temporary employment provide support for the view that temporary employment is used by some workers as a transition to regular employment. ${ }^{18}$

\section{Brief Comments on the Results on Alternative Employment Arrangements}

The advantage of using the matched DWS-CAEAS data is that detailed information on employment arrangements allows the identification of alternative employment arrangements held subsequent to job loss. But there are at least two disadvantages. First, the sample size is relatively small due to 1 ) the relatively small fraction of workers who report a job loss in the DWS, 2) the relatively small fraction of individuals who report being in an alternative employment arrangement in the CAEAS, and 3) the inability to match a substantial number of individuals across the two surveys. The second disadvantage is that the information on alternative work arrangements refers to a point in time substantially after the time of job loss (at least 14 months later at best and up to four years at worst). To the extent that alternative employment arrangements as a response to job loss are part of a transitory phase, these matched data might substantially understate the use of alternative employment arrangements as a response to job loss. ${ }^{19}$

While I cannot address these issues directly due to data limitation, I now turn to analysis of part-time employment and its relationship with job loss. I do this for three reasons. First, part-time employment, particularly involuntary part-time employment, may be experienced by job losers in a transition period. Second, information on parttime employment is available as part of the basic CPS questionnaire and so is available at the DWS date (one year more proximate to the job loss) as well as at the CAEAS date. Third, because observations on part-time status are available at two points in time in the

18 While not presented here, probit models of the probability of employment of the various types that control for age, education, sex, race, marital status, and the interaction of sex and marital status along with time since job loss do not change these findings.

19 For example, the estimates suggest that the likelihood of temporary employment arrangements falls by about 2 percentage points with each year since job loss. Simple (weighted) tabulation of the data show that 11.9 percent of those employed in at the CAEAS date who had lost jobs in the year prior to the relevant DWS (two years prior to the CAEAS) were in temporary jobs at then CAEAS date. If the point estimate is taken seriously (admittedly a stretch given the out-of-sample nature of this calculation), then about 14 percent of those displaced in the year prior to the CAEAS would be predicted to be in temporary jobs at the CAEAS date. 
matched data (three points in time for job losers), I can address directly the question of the transitory nature of part-time employment subsequent to job loss.

\section{Job Loss and Part-Time Employment}

I begin the analysis of job loss and part-time employment by carrying out an analysis of part-time employment using the matched DWS-CAEAS data that parallels the analysis presented above for alternative employment arrangements. The matched data have measures of part-time employment at two points in time: the DWS date and the CAEAS date. ${ }^{20}$ Since the DWS date is more proximate to the date of job loss (1-3 years) than the CAEAS date (2-4 years), a comparison of the part-time rates at the two dates as well as measures of the transition rates from part-time to full-time employment can shed some light on the extent to which part-time employment is used as a transition strategy after job loss.

Table 7 provides strong evidence that involuntary part-time employment is an important transition strategy for job losers. The first three columns of the table contain the full-time, voluntary part-time, and involuntary part-time rates for non-losers and for job losers measured at the DWS date. Also presented is the job-loss differential in these rates. The full-time employment rate is 5.6 percentage points lower for job losers than for nonlosers. This is almost entirely accounted for by a 4.9 percentage point higher involuntary part-time rate for job losers relative to non-losers. The important contrast is with the tabulations in the last three columns of table 8 , which provide the same breakdown for part-time employment status at the CAEAS date. Here there is no significant difference in the full-time rate between job-losers and non-losers and only a 1.5 percentage point higher involuntary part-time rate for job losers relative to non-losers.

As before, the next step is to carry out multivariate analyses of the probability of the three full/part-time categories in order to estimate the job-loss differentials in employment probabilities controlling for demographic characteristics. The first row of table 8 contains estimates of the adjusted job-loss differentials from simple probit models of the probability

20 The DWS also has information on full/part-time status on the lost job. I use this information later in this section. 
of employment of the various types as a function of job-loss status, age, education, sex, marital status, the interaction of sex and marital status, and race. ${ }^{21}$ The estimates in the first three columns of table 8 use the subset of the matched sample consisting of those individuals who are employed at the DWS date while the estimates in the last three columns use the subset of the matched sample consisting of those individuals who are employed at the CAEAS date. ${ }^{22}$

The first row of table 8 contains the adjusted job-loss differentials for the overall sample are similar to the unadjusted differences found in table 7 . Job losers are about 6.1 percentage points less likely than non-losers to be in full-time jobs at the DWS date, and this difference shrinks to 2.2 percentage points by the CAEAS date. There is a small positive relationship between job loss and voluntary part-time employment at the DWS date that is not apparent at the CAEAS date. Finally, job losers are 3.5 percentage points more likely to be involuntarily in part-time jobs at the DWS date, and this difference falls to 1.3 percentage points by the CAEAS date.

The estimates in table 7 and the first row of table 8 present the consistent picture that involuntary part-time employment is experienced disproportionately by job losers. However, the differential rate of involuntary part-time employment falls with time, suggesting that this is a transitional experience for many job losers.

The probit models underlying the estimates in the first row of table 8 control for observable differences across workers, but they constrain the job-loss differential in the full/part-time employment outcomes to be the same for all types of workers. As before, I relax this restriction by estimating separate probit models for various categories of workers. Each of these probit models contain the same set of variables as the overall model (omitting the set of variables on which the particular subsample is stratified). The remaining rows

21 These differentials are the coefficients on the job-loss variable in the probit models normalized to represent the derivative of the probability of the outcome with respect to a change in job loss status. See note 16 for details.

22 While the full estimates of the probit model are not presented here, the estimates based on both samples verify the common finding that married females are substantially less likely to be employed full time, a fact that is largely accounted for by a substantially higher probability of being employed voluntarily in a part-time job. The results also support the common finding that the probability of involuntary part-time employment falls monotonically with education. 
of table 8 contain the normalized probit coefficients of the job-loss dummy variable from each of these models for 1) separate models by sex and marital status, 2) separate models by educational category, and 3) separate models by age category.

The adjusted job-loss differentials estimated from separate probit models by sex and marital status yield results that are not very different from those derived from the overall sample. The major exception is that only married females have a significant job loss differential in the rate of involuntary part-time employment remaining at the CAEAS date.

The adjusted job-loss differentials estimated from separate probit models by educational category imply that the job loss differentials in full-time employment for workers in all educational categories are significantly negative at the DWS date. This is offset by significant positive job loss differentials in involuntary part-time employment for workers in all educational categories. Moving forward one year to the CAEAS date, the job-loss differentials in full-time employment disappears for workers in the lowest and highest educational categories but remains substantial for workers in the intermediate educational categories.

With regard to age, the job-loss differential in full-time employment for the oldest workers is large and negative at the DWS date and remains so one year later at the CAEAS date. This is offset roughly equally by positive job-loss differentials in voluntary and involuntary part-time employment for the oldest workers.

To summarize, the evidence in tables 7 and 8 provide clear evidence that job losers are disproportionately employed involuntarily in part-time jobs. The evidence is also clear that much of this involuntary part-time employment is part of a transition process to full time employment.

\section{The Use of Part-Time Employment by Losers of Full-Time Jobs}

The 1994 and 1996 DWSs provide information on the full/part-time status of the lost job for those who lose jobs due to a plant closing, slack work, or position/shift abolished. For the part-time job losers, there is no information on whether the individual was part-time 
voluntarily or involuntarily. ${ }^{23}$ Analysis of post-job-loss full/part-time employment status conditioning on the full/part-time status on the lost job can provide more information on the extent to which part-time employment, both voluntary and involuntary, is used by job losers. Of particular interest is the post-displacement experience of losers of full-time jobs since these workers show more commitment to full-time work than do part-time workers, many of whom are part-time voluntarily. ${ }^{24}$

Table 9 contains information, based on the matched data, on the post-displacement full/part-time status of workers broken down by the full/part-time status on the lost job. The first row of table 9 reproduces the first row of table 7 , and it shows the postdisplacement full/part-time status of those workers who did not report losing a job. The second and third rows report the post-displacement full/part-time employment status of full-time job losers and part-time job losers respectively. The first three columns report the fraction in each full/part-time status at the DWS date, and the last three columns report the fraction in each full/part-time status at the CAEAS date.

Among those employed at the relevant survey date, there is a sharp contrast between the full-time job losers and the part-time job losers. By the DWS survey date, the fraction of full-time job losers who are working full-time is virtually identical to the fraction of nonlosers who are working full-time ( 84.3 percent vs. 85.0 percent), and, by the CAEAS date, the fraction of full-time job losers who are working full-time is significantly larger than the fraction of non-losers who are working full-time (88.3 percent vs. 85.4 percent, p-value of difference $<0.00005)$. It is also the case that full-time job losers are less likely than non-losers to be voluntarily part-time and more likely than non-losers to be involuntarily part-time at the DWS date. By the CAEAS date, the gap in the voluntary part-time rates increases while the gap in the involuntary part-time rate decreases. This pattern is a result of the fact that the pool of non-losers contains a core of individuals who are

23 Of the 2598 job losers for whom we have information on the full/part-time status on the lost job, 10.9 percent (weighted) reported losing a part-time job. In contrast, 15.0 percent (weighted) of those workers who did not lose a job were employed part-time at the DWS survey date. Thus, the job-loss rate on full-time jobs appears to be higher than the job-loss rate on part-time jobs.

24 Tabulations of the February 1994 and 1996 CPS data yields the result that 68.1 percent of part-time workers are part-time for voluntary reasons. 
voluntarily part-time as a result of labor supply choices while the full-time job losers have shown evidence of a commitment to full-time work. This interpretation of the evidence is further supported by the post-displacement full/part-time status of the part-time job losers, who are substantially less likely thatn full-time job losers to be employed full time at either the DWS date or the CAEAS date.

\section{Transitions in Full/Part-Time Status between the DWS Date and the CAEAS Date}

The analysis in the previous subsection strongly suggests that there is heterogeneity among the workforce in general and among job losers in particular in preferences for full-time work. There may also be further heterogeneity in the ability to find and hold a full-time job. Implicit in the earlier discussion is the idea that full-time workers are committed to full-time work, but it is surely the case that some full-time workers move to part-time work and vice versa, even without a job loss. This presumably reflects changes in individual constraints and in market conditions over time. In this subsection, I examine individual transitions in full/part-time status between the DWS date and the CAEAS date separately for non-losers and for full-time and part-time job losers.

Conditioning on full/part-time status at the DWS date, I use the non-losers as a "control group", and I measure their transition rates to full-time, voluntary part-time, and involuntary part-time employment by the CAEAS date. These are, in a sense, the "natural" rates of transition. I then contrast these transition rates with the transition rates for full- and part-time job losers. These analyses provide further information on the incidence and persistence of part-time employment subsequent to job loss.

Table 10 contains the core of this analysis. The first panel contains the transition rates of workers who were working full-time at the DWS date. In the control group of non-losers, 95.4 percent remained employed full-time a year later while 2.6 percent moved to voluntary part-time status and 2.0 percent moved to involuntary part-time status. Think of these as the natural transition rates. The picture is not far different for losers of full-time jobs who were employed full-time at the DWS date. However, part-time job losers who are employed full-time at the DWS date are less likely to remain in full-time employment (92.6 percent) 
and more likely to move to involuntary part-time status (4.7 percent).$^{25}$

The second and third panels of table 10 contains the transition rates of workers who were in voluntary and involuntary part-time status respectively at the DWS date. The key finding is that a substantially higher fraction of full-time job losers (relative to either non-losers or part-time jobs losers) moved from part-time jobs to full-time jobs between the DWS date and the CAEAS date. This is further evidence that full-time job losers find themselves in part-time employment as a transition to reemployment full-time.

\section{The Interaction of Alternative Employment Arrangements and Full/Part-Time Status}

I have established that temporary and part-time employment, particularly involuntary part-time employment, are important transitional outcomes for displaced workers. Further, the breakdowns in table 2 clearly show that temporary workers are the least likely of all groups to be in full-time jobs. Temporary workers are more likely than other workers to be both voluntarily and involuntarily part-time. In this section, I briefly investigate how the interactions between alternative employment arrangements and full/part-time status generally and between temporary work and part-time status specifically are related to job loss.

Table 11 contains breakdowns, using the merged data, of full/part-time status by employment status at the CAEAS date separately for non-losers and job losers. The top panel of the table uses the merged data to reproduce the breakdowns in table 2 (which used the entire 95 and 97 CAEASs), and the results are very similar. This verifies that the merged sample is not substantially different in these dimensions than the overall sample. The second panel of table 11 contains the same breakdowns for non-losers. These breakdowns are very close to those for the overall sample, and this is not surprising given that only a small fraction of the sample consists of job losers. The third panel of the table contains the breakdowns for all employed job losers, and the there are some important differences here.

25 There are relatively few part-time job losers in the sample used for this analysis (173 total) and even fewer who are employed full time at the DWS date (92). As a result the standard errors on the transition rates for part-time job losers are relatively large, the differences between pthese transition rates and those for other groups are not generally statistically significant at conventional levels. 
A significantly higher fraction of temporary workers who lost jobs are employed full-time at the CAEAS date relative to non-losers $(12.0$ percentage points, $\mathrm{p}$-value $<0.0000001)$. This is entirely accounted for by an 11.8 percentage point difference in the voluntary part-time rate between non-losers and job losers ( $\mathrm{p}$-value $<0.0000001$ ).

The contrast between non-losers and job losers is even more striking when considering only full-time job losers. The bottom panel of table 11 contains breakdowns for 1772 full-time job losers who are employed at the CAEAS date. Full-time job losers who are employed in temporary jobs at the CAEAS date are even more likely to be in full-time jobs (76.8 percent) and even less likely to be in voluntary part-time jobs (10.9 percent).

These results imply that temporary jobs are often taken by workers who have a preference for part-time work. It may be that temporary employment arrangements are an efficient arrangement for these workers. However, it is clear that among job losers, particularly those who lost full-time jobs, temporary jobs are transitional outcomes that are more likely than the usual temporary job to be characterized by full-time hours.

\section{Final Remarks}

It is clear that alternative employment arrangements are an important feature of the U.S. labor market. Tabulation of the February 1995 and 1997 CAEASs showed that 17.5 percent of workers were self-employed or in temporary jobs. Additionally, 15.3 percent of workers in these same surveys were employed part-time (10.8 percent voluntary, 4.5 percent involuntary). My analysis of the matched DWS-CAEAS data shows that job losers are more likely than non-losers to use alternative and part-time employment arrangements. I find that job losers are significantly more likely than non-losers to be in temporary jobs (including on-call work and contract work) and that job losers are significantly more likely than non-losers to be employed involuntarily part-time.

I also find that the likelihood of temporary and involuntary part-time employment falls with time since job loss. Thus, it appears that these alternative employment arrangements are often part of a transitional process subsequent to job loss leading to regular fulltime permanent employment. In this respect, temporary employment by job-losers is of a different character than temporary employment by non-losers. Job losers who find 
employment in temporary jobs are more likely to be working full-time while non-losers who are employed in temporary jobs are more likely to be working voluntarily part-time. 


\section{References}

Abraham, Katharine G. "Restructuring the Employment Relationship: The Growth of Market-Mediated Work Arrangements," in Katharine G. Abraham and Robert B. McKersie, eds., New Developments in the Labor Market: Toward a New Institutional Paradigm, Cambridge MA: MIT Press, 1990, pp. 85-119.

Abraham, Katharine G. and Susan K. Taylor. 'Firms' Use of Outside Contractors: Theory and Evidence," Journal of Labor Economics 14 (July 1996): pp. 394-424.

Belous, Richard S. The Contingent Economy, Washington, D.C., National Planning Association, 1989 .

Blank, Rebecca M. "The Role of Part-Time Work in Women's Labor Market Choices Over Time," American Economic Review 79 (May 1989): pp.295-299.

Blank, Rebecca M. "Are Part-Time Jobs Bad Jobs?," in A Future of Lousy Jobs?, Gary Burtless, ed., The Brookings Institution, 1990.(a)

Blank, Rebecca M. "Understanding Part-Time Work," in Research in Labor Economics, Volume 11. Laurie J. Bassi and David L. Crawford, eds., JAI Press, Inc. 1990.(b)

Farber, Henry S. "The Incidence and Costs of Job Loss: 1982-91," Brookings Papers on Economic Activity: Microeconomics, (1993,1), 73-119.

Farber, Henry S. "The Changing Face of Job Loss in the United States: 1981-1995," Brookings Papers on Economic Activity: Microeconomics, 1997: 55-128.

Farber, Henry S. "Trends in Long-Term Employment in the United States, 1979-96," Working Paper No. 384, Industrial Relations Section, Princeton University, July 1997.(b)

Farber, Henry S. "Job Creation in the United States: Good Jobs or Bad?" Working Paper No. 385, Industrial Relations Section, Princeton University, July 1997.(c)

Farber, Henry S. and Helen Levy. "Recent Trends in Employer-Sponsered Health Insurance: Are Bad Jobs Getting Worse?" Working Paper No. 402, Industrial Relations Section, Princeton University, July 1998.

Ferber, Marianne and Jane Waldfogel. " 'Contingent' Work: Blessing and/or Curse," Radcliffe Public Policy Institute mimeo, 1996.

Gardner, Jennifer M. "Worker Displacement: A Decade of Change," Monthly Labor Review 118 (April 1995): pp. 45-57. 
Golden, Lonnie and Eileen Appelbaum. "What Was Driving the 1982-88 Boom In Temporary Employment?," American Journal of Economics and Sociology 51 (October 1992): pp. 473-493.

Houseman, Susan N. "Temporary, Part-Time and Contract Employment in the United States: New Evidence from an Employer Survey," W.E. Upjohn Institute for Employment Research, mimeo, February 1997.

Howe, Wayne J. "Temporary Help Workers: Who They Are, What Jobs They Hold," Monthly Labor Review 109 (November 1986): pp. 45-47.

Kletzer, Lori G. "Returns to Seniority after Permanent Job Loss," American Economic Review 79 (June 1989): pp. 536-543.

Montgomery, Mark and James Cosgrove. "The Effect of Employee Benefits on the Demand for Part-Time Workers," Industrial and Labor Relations Review 47 (October 1993): pp. $87-98$.

Neal, Derek. "Industry-Specific Capital: Evidence from Displaced Workers," Journal of Labor Economics 13 (October 1995): pp. 653-677.

Parent, Daniel. "Industry-Specific Capital: Evidence from the NLSY and the PSID," Working Paper No. 350, Industrial Relations Section, Princeton University, November 1995.

Podgursky, Michael and Paul Swaim. "Job Displacement Earnings Loss: Evidence from the Displaced Worker Survey,"" Industrial and Labor Relations Review 41 (October 1987): pp. 17-29.

Polivka, Anne. "Are Temprorary Help Agency Workers Substitutes for Direct Hire Temps? Searching for an Alternative Explanation for of Growth in the Temporary Help Industry," mimeo, U.S. Bureau of Labor Statistics, May 1996.

Segal, Lewis M. and Daniel G. Sullivan. "The Growth of Temporary Services Work," Journal of Economic Perspectives 11 (Spring 1997): pp. 117-136.

Tilly, Chris. "Reasons for the Continuing Growth of Part-Time Employment," Monthly Labor Review 114 (March 1991): pp. 10-18.

Topel, Robert. "Specific Capital and Unemployment: Measuring the Costs and Consequences of Job Loss," Carnegie Rochester Conference Series on Public Policy 33 (1990): pp. 181-214. 
TABLE 1: Fraction of Employed with Specific Alternative Employment Arrangements February 1995 and 1997 CAEAS's

Workers aged 20-66

\begin{tabular}{lccccccc} 
Group & Regular & Contractor & Other-SE & Temporary & Full-Time & Vol PT & Invol PT \\
\hline All & 0.825 & 0.059 & 0.054 & 0.062 & 0.847 & 0.108 & 0.045 \\
& $(0.001)$ & $(0.001)$ & $(0.001)$ & $(0.001)$ & $(0.001)$ & $(0.001)$ & $(0.001)$ \\
\hline Male & 0.802 & 0.076 & 0.061 & 0.061 & 0.918 & 0.045 & 0.036 \\
& $(0.002)$ & $(0.001)$ & $(0.001)$ & $(0.001)$ & $(0.002)$ & $(0.001)$ & $(0.001)$ \\
Female & 0.851 & 0.039 & 0.046 & 0.064 & 0.765 & 0.180 & 0.055 \\
& $(0.002)$ & $(0.001)$ & $(0.001)$ & $(0.001)$ & $(0.002)$ & $(0.001)$ & $(0.001)$ \\
\hline Ed<12 & 0.823 & 0.053 & 0.047 & 0.077 & 0.818 & 0.087 & 0.094 \\
& $(0.004)$ & $(0.002)$ & $(0.002)$ & $(0.003)$ & $(0.004)$ & $(0.003)$ & $(0.002)$ \\
Ed=12 & 0.841 & 0.054 & 0.052 & 0.053 & 0.853 & 0.097 & 0.050 \\
& $(0.002)$ & $(0.001)$ & $(0.001)$ & $(0.001)$ & $(0.002)$ & $(0.002)$ & $(0.001)$ \\
Ed 13-15 & 0.828 & 0.054 & 0.049 & 0.069 & 0.810 & 0.148 & 0.042 \\
& $(0.002)$ & $(0.001)$ & $(0.001)$ & $(0.001)$ & $(0.002)$ & $(0.002)$ & $(0.001)$ \\
Ed $\geq 16$ & 0.803 & 0.071 & 0.064 & 0.062 & 0.890 & 0.084 & 0.026 \\
& $(0.002)$ & $(0.001)$ & $(0.001)$ & $(0.001)$ & $(0.002)$ & $(0.002)$ & $(0.001)$ \\
\hline age 20-24 & 0.851 & 0.012 & 0.014 & 0.123 & 0.705 & 0.226 & 0.070 \\
& $(0.004)$ & $(0.002)$ & $(0.002)$ & $(0.002)$ & $(0.003)$ & $(0.003)$ & $(0.002)$ \\
age 25-34 & 0.853 & 0.042 & 0.035 & 0.070 & 0.868 & 0.088 & 0.044 \\
& $(0.002)$ & $(0.001)$ & $(0.001)$ & $(0.001)$ & $(0.002)$ & $(0.002)$ & $(0.001)$ \\
age 35-44 & 0.826 & 0.066 & 0.057 & 0.052 & 0.871 & 0.090 & 0.039 \\
& $(0.002)$ & $(0.001)$ & $(0.001)$ & $(0.001)$ & $(0.002)$ & $(0.002)$ & $(0.001)$ \\
age 45-54 & 0.810 & 0.076 & 0.072 & 0.043 & 0.885 & 0.075 & 0.040 \\
& $(0.003)$ & $(0.002)$ & $(0.002)$ & $(0.002)$ & $(0.002)$ & $(0.002)$ & $(0.001)$ \\
age 55-64 & 0.767 & 0.088 & 0.095 & 0.050 & 0.812 & 0.139 & 0.049 \\
& $(0.004)$ & $(0.002)$ & $(0.002)$ & $(0.002)$ & $(0.003)$ & $(0.003)$ & $(0.002)$
\end{tabular}

Note: Based on tabulations from the February 1995 and 1997 Contingent and Alternative Employment Arrangements Supplements to the CPS. See the text for definitions of the alternative employment arrangements and the full/part-time statuses. The classifications of employment arrangements in the first four columns are independent of full/part-time status classifications. All fractions are weighted by CPS sampling weights. The numbers in parentheses are standard errors. $\mathrm{n}=102318$. 
TABLE 2: Part-Time Status by Employment Arrangement

February 1995 and 1997 CAEAS's

Workers aged 20-66

(row fractions)

\begin{tabular}{lrrr} 
Group & Full-Time & Vol P-T & Invol PT \\
\hline Regular & 0.874 & 0.092 & 0.034 \\
Contractor & 0.756 & 0.148 & 0.097 \\
Other-SE & 0.781 & 0.151 & 0.069 \\
Temporary & 0.638 & 0.244 & 0.119 \\
\hline All & 0.847 & 0.108 & 0.045
\end{tabular}

Note: Based on tabulations from the February 1995 and 1997 Contingent and Alternative Employment Arrangements Supplements to the CPS. See the text for definitions of categories. $n=102318$.

TABLE 3: Fraction of Individuals with Specific Alternative Employment Arrangements

By Job Loss Status

Matched DWS - CAEAS Data

Individuals aged 20-64 in DWS

\begin{tabular}{lcccccc} 
Group & Regular & Contractor & Other-SE & Temporary & Unemployed & NILF \\
\hline Non-Losers & 0.613 & 0.047 & 0.044 & 0.035 & 0.028 & 0.234 \\
& $(0.002)$ & $(0.001)$ & $(0.001)$ & $(0.001)$ & $(0.001)$ & $(0.002)$ \\
Job Losers & 0.599 & 0.046 & 0.021 & 0.078 & 0.090 & 0.166 \\
& $(0.007)$ & $(0.003)$ & $(0.003)$ & $(0.003)$ & $(0.003)$ & $(0.006)$ \\
\hline Difference & -0.014 & -0.001 & -0.023 & 0.043 & 0.062 & -0.068 \\
& $(0.008)$ & $(0.003)$ & $(0.003)$ & $(0.003)$ & $(0.003)$ & $(0.007)$
\end{tabular}

Note: Based on tabulations from the matched February 1994 and 1996 DWSs with the February 1995 and 1997 CAEASs respectively. See the text for definitions of the job type classifications. Workers are classified as unemployed and not in the labor force (NILF) according to the standard CPS definitions. See the text for a description of the matching procedure. All fractions are weighted by CPS sampling weights. The numbers in parentheses are standard errors. $n=45063$.

TABLE 4: Fraction of Employed with Specific Alternative Employment Arrangements

By Job Loss Status

Matched DWS - CAEAS

Workers aged 20-64 at DWS Date

\begin{tabular}{lcccc}
\multicolumn{5}{c}{ All Workers $(\mathrm{n}=33296)$} \\
Group & Regular & Contractor & Other-SE & Temporary \\
\hline Non-Losers & 0.830 & 0.063 & 0.060 & 0.047 \\
& $(0.002)$ & $(0.001)$ & $(0.001)$ & $(0.001)$ \\
Job Losers & 0.805 & 0.062 & 0.029 & 0.105 \\
& $(0.007)$ & $(0.004)$ & $(0.004)$ & $(0.004)$ \\
\hline Difference & -0.025 & -0.001 & -0.031 & 0.057 \\
& $(0.007)$ & $(0.005)$ & $(0.004)$ & $(0.004)$
\end{tabular}

Note: Based on tabulations from the matched February 1994 and 1996 Displaced Workers Supplments to the CPS with the February 1995 and 1997 Contingent and Alternative Employment Arrangements Supplements to the CPS respectively. See the text for a definitions of the job type classifications. See the text for a description of the matching procedure. All fractions are weighted by CPS sampling weights. The numbers in parentheses are standard errors. $n=33296$. 
TABLE 5: Lost-Job Differential in Probability of Employment by Type Matched DWS - CAEAS Data

Individuals Aged 20-64 at DWS Date and Employed at CAEAS Date

Based on Probit Analysis

Estimated Normalized to Represent Marginal Effects on Probability of Outcome

(standard errors)

\begin{tabular}{llclc} 
Group & Regular & Contractor & Other-SE & Temporary \\
\hline All & -0.0277 & 0.0010 & -0.0313 & 0.0414 \\
& $(0.0068)$ & $(0.0042)$ & $(0.0049)$ & $(0.0033)$ \\
\hline Single Male & -0.0339 & -0.0073 & -0.0242 & 0.0514 \\
& $(0.0168)$ & $(0.0107)$ & $(0.0101)$ & $(0.0096)$ \\
Married Male & -0.0132 & -0.0039 & -0.0548 & 0.0416 \\
& $(0.0119)$ & $(0.0085)$ & $(0.0095)$ & $(0.0046)$ \\
Single Female & -0.0529 & 0.0133 & 0.0080 & 0.0266 \\
& $(0.0126)$ & $(0.0052)$ & $(0.0055)$ & $(0.0090)$ \\
Married Female & -0.0259 & -0.0001 & -0.0410 & 0.0439 \\
& $(0.0132)$ & $(0.0080)$ & $(0.0106)$ & $(0.0065)$ \\
\hline Ed<12 & -0.0105 & -0.0066 & -0.0314 & 0.0354 \\
& $(0.0252)$ & $(0.0147)$ & $(0.0174)$ & $(0.0137)$ \\
Ed=12 & -0.0196 & -0.0149 & -0.0308 & 0.0422 \\
& $(0.0116)$ & $(0.0076)$ & $(0.0084)$ & $(0.0052)$ \\
Ed 13-15 & -0.0123 & 0.0011 & -0.0317 & 0.0332 \\
& $(0.0118)$ & $(0.0069)$ & $(0.0079)$ & $(0.0064)$ \\
Ed $\geq 16$ & -0.0614 & 0.0183 & -0.0311 & 0.0514 \\
& $(0.0116)$ & $(0.0076)$ & $(0.0084)$ & $(0.0052)$ \\
\hline Age 20-24 & -0.0156 & 0.0079 & -0.0042 & 0.0055 \\
& $(0.0251)$ & $(0.0056)$ & $(0.0084)$ & $(0.0229)$ \\
Age 25-34 & -0.0189 & 0.0027 & -0.0121 & 0.0254 \\
& $(0.0122)$ & $(0.0071)$ & $(0.0071)$ & $(0.0076)$ \\
Age 35-44 & -0.0378 & -0.0089 & -0.0463 & 0.0564 \\
& $(0.0118)$ & $(0.0081)$ & $(0.0092)$ & $(0.0052)$ \\
Age 45-54 & -0.0346 & 0.0161 & -0.0343 & 0.0342 \\
& $(0.0143)$ & $(0.0090)$ & $(0.0113)$ & $(0.0057)$ \\
Age 55-64 & 0.0014 & -0.0305 & -0.0632 & 0.0569 \\
& $(0.0248)$ & $(0.0166)$ & $(0.0200)$ & $(0.0100)$
\end{tabular}

Note: The estimates are the normalized coefficients on the lost-job dummy variable from separate probit models where the dependent variable is the indicator variable for the type of employment in each column. Other variables included in the probit model include, where appropriate, a constant, three dummy variables for education category, four dummy variables for age category, and dummy variables for sex, marital status, the interaction of sex and marital status, and race. The estimates are based on the matched February 1994 and 1996 DWSs with the February 1995 and 1997 CAEASs respectively. Individuals aged 20-64 in the February 1994 and 1996 DWSs and were employed in at the CAEAS date. See the text for a description of the employment types and for a description of the matching procedure. See note 16 for details of the normalization. The normalized asymptotic standard errors are in parentheses. All analyses are weighted by CPS sampling weights from 1994 or 1996 . 
TABLE 6: Breakdown of Employment Arrangements by Years Since Job Loss

Matched DWS - CAEAS

Individuals Employed at CAEAS Date

Individuals Aged 20-64 at DWS Date

\begin{tabular}{lcccc} 
Yrs Since Loss & Regular & Contractor & Other-SE & Temporary \\
\hline 2 Years & 0.795 & 0.055 & 0.032 & 0.118 \\
& $(0.013)$ & $(0.008)$ & $(0.008)$ & $(0.007)$ \\
3 Years & 0.816 & 0.058 & 0.029 & 0.097 \\
& $(0.015)$ & $(0.010)$ & $(0.009)$ & $(0.009)$ \\
4 Years & 0.829 & 0.074 & 0.019 & 0.078 \\
& $(0.015)$ & $(0.010)$ & $(0.009)$ & $(0.009)$ \\
\hline No Loss & 0.830 & 0.063 & 0.060 & 0.047 \\
& $(0.002)$ & $(0.001)$ & $(0.001)$ & $(0.001)$
\end{tabular}

Note: Based on tabulations from the Merged February 1994 and 1996 DWSs with the February 1995 and 1997 CAEASs respectively. See the text for definitions of the job type classifications and for a description of the matching procedure. All fractions are weighted by CPS sampling weights from 1994 or 1996 . The numbers in parentheses are standard errors. $n=32321$ including 2056 job losers.

TABLE 7: Fraction of Employed with Specific Full/Part-Time Employment Arrangements

By Job Loss Status

Matched DWS - CAEAS

Workers aged 20-64 at DWS Date

\begin{tabular}{lcccccc} 
Group & $\begin{array}{r}\text { Full Time } \\
\text { at DWS }\end{array}$ & $\begin{array}{c}\text { Vol P-T } \\
\text { at DWS }\end{array}$ & $\begin{array}{r}\text { Invol P-T } \\
\text { at DWS }\end{array}$ & $\begin{array}{c}\text { Full Time } \\
\text { at CAEAS }\end{array}$ & $\begin{array}{c}\text { Vol P-T } \\
\text { at CAEAS }\end{array}$ & $\begin{array}{c}\text { Invol P-T } \\
\text { at CAEAS }\end{array}$ \\
\hline Non-Loser & 0.850 & 0.109 & 0.041 & 0.854 & 0.107 & 0.039 \\
& $(0.002)$ & $(0.002)$ & $(0.001)$ & $(0.002)$ & $(0.002)$ & $(0.001)$ \\
Job Loser & 0.794 & 0.116 & 0.090 & 0.842 & 0.104 & 0.054 \\
& $(0.007)$ & $(0.006)$ & $(0.004)$ & $(0.006)$ & $(0.005)$ & $(0.004)$ \\
\hline Difference & -0.056 & 0.008 & 0.049 & -0.011 & -0.003 & 0.015 \\
& $(0.007)$ & $(0.006)$ & $(0.004)$ & $(0.007)$ & $(0.006)$ & $(0.004)$
\end{tabular}

Note: Based on tabulations from the matched February 1994 and 1996 DWSs with the February 1995 and 1997 CAEASs respectively. See the text for definitions of the job type classifications and for a description of the matching procedure. All fractions are weighted by CPS sampling weights from 1994 or 1996 . The numbers in parentheses are standard errors. $n=33705$ at DWS date and $n=33296$ at CAEAS date. 
TABLE 8: Lost-Job Differential in Full/Part Time Status

Matched DWS - CAEAS Data

Individuals Aged 20-64 at DWS Date and Employed at CAEAS Date

Based on Probit Analysis

Estimated Normalized to Represent Marginal Effects on Probability of Outcome

(standard errors)

\begin{tabular}{lcccccc} 
Group & $\begin{array}{c}\text { Full Time } \\
\text { at DWS }\end{array}$ & $\begin{array}{c}\text { Vol P-T } \\
\text { at DWS }\end{array}$ & $\begin{array}{c}\text { Invol P-T } \\
\text { at DWS }\end{array}$ & $\begin{array}{c}\text { Full Time } \\
\text { at CAEAS }\end{array}$ & $\begin{array}{c}\text { Vol P-T } \\
\text { at CAEA }\end{array}$ & $\begin{array}{c}\text { Invol P-T } \\
\text { at CAEAS }\end{array}$ \\
\hline All & -0.0613 & 0.0168 & 0.0354 & -0.0219 & 0.0075 & 0.0130 \\
& $(0.006)$ & $(0.0049)$ & $(0.0030)$ & $(0.0059)$ & $(0.0047)$ & $(0.0032)$ \\
\hline Single Male & -0.0445 & 0.0069 & 0.0355 & -0.0124 & 0.0049 & 0.0073 \\
& $(0.0145)$ & $(0.0105)$ & $(0.0091)$ & $(0.0137)$ & $(0.0098)$ & $(0.0091)$ \\
Married Male & -0.0394 & 0.0104 & 0.0263 & -0.0225 & 0.0115 & 0.0095 \\
& $(0.0053)$ & $(0.0037)$ & $(0.0036)$ & $(0.0052)$ & $(0.0032)$ & $(0.0038)$ \\
Single Female & -0.0744 & 0.0164 & 0.0480 & -0.0099 & -0.0004 & 0.0097 \\
& $(0.0164)$ & $(0.0138)$ & $(0.0089)$ & $(0.0158)$ & $(0.0128)$ & $(0.0091)$ \\
Married Female & -0.0920 & 0.0413 & 0.0410 & -0.0293 & 0.0012 & 0.0239 \\
& $(0.0161)$ & $(0.0151)$ & $(0.0066)$ & $(0.0160)$ & $(0.0152)$ & $(0.0068)$ \\
\hline Ed<12 & -0.0775 & -0.0056 & 0.0667 & -0.0093 & -0.0276 & 0.0277 \\
& $(0.0243)$ & $(0.0183)$ & $(0.0162)$ & $(0.0255)$ & $(0.0176)$ & $(0.0173)$ \\
Ed=12 & -0.0666 & 0.0279 & 0.0334 & -0.0422 & 0.0282 & 0.0122 \\
& $(0.0106)$ & $(0.0080)$ & $(0.0062)$ & $(0.0103)$ & $(0.0077)$ & $(0.0062)$ \\
Ed 13-15 & -0.0666 & 0.0279 & 0.0334 & -0.0422 & 0.0282 & 0.0122 \\
& $(0.0106)$ & $(0.0080)$ & $(0.0062)$ & $(0.0103)$ & $(0.0077)$ & $(0.0062)$ \\
Ed $\geq 16$ & -0.0497 & 0.0036 & 0.0348 & 0.0016 & -0.0108 & 0.0093 \\
& $(0.0114)$ & $(0.0099)$ & $(0.0052)$ & $(0.0112)$ & $(0.0095)$ & $(0.0054)$ \\
\hline Age 20-24 & 0.0276 & -0.0700 & 0.0306 & 0.0409 & -0.0338 & -0.0021 \\
& $(0.0385)$ & $(0.0361)$ & $(0.0197)$ & $(0.0338)$ & $(0.0309)$ & $(0.0165)$ \\
Age 25-34 & -0.0580 & 0.0233 & 0.0271 & -0.0206 & 0.0118 & 0.0076 \\
& $(0.0108)$ & $(0.0087)$ & $(0.0056)$ & $(0.0111)$ & $(0.0086)$ & $(0.0062)$ \\
Age 35-44 & -0.0582 & 0.0095 & 0.0371 & -0.0177 & 0.0060 & 0.0099 \\
& $(0.0099)$ & $(0.0077)$ & $(0.0049)$ & $(0.0096)$ & $(0.0072)$ & $(0.0050)$ \\
Age 45-54 & -0.0676 & 0.0257 & 0.0340 & -0.0209 & 0.0015 & 0.0173 \\
& $(0.0104)$ & $(0.0080)$ & $(0.0056)$ & $(0.0106)$ & $(0.0080)$ & $(0.0060)$ \\
Age 55-64 & -0.1150 & 0.0561 & 0.0492 & -0.0897 & 0.0538 & 0.0316 \\
& $(0.0221)$ & $(0.0189)$ & $(0.0117)$ & $(0.0221)$ & $(0.0192)$ & $(0.0112)$
\end{tabular}

Note: The estimates are the normalized coefficients on the lost-job dummy variable from separate probit models where the dependent variable is the indicator variable for the type full/part-time status in each column. Other variables included in the probit model include, where appropriate, a constant, three dummy variables for education category, four dummy variables for age category, and dummy variables for sex, marital status, the interaction of sex and marital status, and race. The estimates are based on the matched February 1994 and 1996 DWSs with the February 1995 and 1997 CAEASs respectively. Individuals aged 20-64 in the February 1994 and 1996 DWSs and were employed in at the CAEAS date. See the text for a description of the employment types and for a description of the matching procedure. See note 16 for details of the normalization. Normalized asymptotic standard errors are in parentheses. All analyses are weighted by CPS sampling weights from 1994 or 1996. 
TABLE 9: Fraction Employed with Specific Full/Part-Time Employment Arrangements By Job Loss Status and Full/Part-Time Status on Lost Job

Matched DWS - CAEAS

Workers aged 20-64 at DWS Date

(row fractions)

\begin{tabular}{lcccccc} 
Group & $\begin{array}{r}\text { Full Time } \\
\text { at DWS }\end{array}$ & $\begin{array}{c}\text { Vol P-T } \\
\text { at DWS }\end{array}$ & $\begin{array}{r}\text { Invol P-T } \\
\text { at DWS }\end{array}$ & $\begin{array}{r}\text { Full Time } \\
\text { at CAEAS }\end{array}$ & $\begin{array}{r}\text { Vol P-T } \\
\text { at CAEAS }\end{array}$ & $\begin{array}{r}\text { Invol P-T } \\
\text { at CAEAS }\end{array}$ \\
\hline Non-Loser & 0.850 & 0.109 & 0.041 & 0.854 & 0.107 & 0.039 \\
& $(0.002)$ & $(0.002)$ & $(0.001)$ & $(0.002)$ & $(0.002)$ & $(0.001)$ \\
F-T Job Loser & 0.843 & 0.078 & 0.079 & 0.883 & 0.066 & 0.051 \\
& $(0.009)$ & $(0.008)$ & $(0.005)$ & $(0.008)$ & $(0.007)$ & $(0.005)$ \\
P-T Job Loser & 0.500 & 0.360 & 0.140 & 0.602 & 0.293 & 0.105 \\
& $(0.025)$ & $(0.022)$ & $(0.014)$ & $(0.025)$ & $(0.021)$ & $(0.014)$
\end{tabular}

Note: Based on tabulations from the Merged February 1994 and 1996 DWSs with the February 1995 and 1997 CAEASs respectively. See the text for a definitions of the job type classifications and for a description of the matching procedure. All fractions are weighted by CPS sampling weights from 1994 or 1996 . The numbers in parentheses are standard errors. $n=32709$ at DWS date and $n=32246$ at CAEAS date. 
TABLE 10: Fraction of Employed by Full/Part-Time Employment Arrangement at CAEAS Date By Job Loss Status and Full/Part-Time Status on Lost Job and Job at DWS Date

Matched DWS - CAEAS

Workers aged 20-64 at DWS Date

\begin{tabular}{|c|c|c|c|}
\hline \multirow{3}{*}{ Group } & \multicolumn{2}{|c|}{ (row fractions) } & \multirow{3}{*}{$\begin{array}{l}\text { Invol P-T } \\
\text { at CAEAS }\end{array}$} \\
\hline & Full Time & Vol P-T & \\
\hline & at CAEAS & at CAEAS & \\
\hline \multicolumn{4}{|l|}{ F-T at DWS } \\
\hline \multirow[t]{2}{*}{ Non-Loser } & 0.954 & 0.026 & 0.020 \\
\hline & $(0.001)$ & $(0.001)$ & $(0.001)$ \\
\hline \multirow[t]{2}{*}{ F-T Job Loser } & 0.961 & 0.015 & 0.024 \\
\hline & $(0.006)$ & $(0.004)$ & $(0.004)$ \\
\hline \multirow[t]{2}{*}{ P-T Job Loser } & 0.926 & 0.027 & 0.047 \\
\hline & $(0.023)$ & $(0.017)$ & $(0.015)$ \\
\hline \multicolumn{4}{|l|}{ Vol P-T at DWS } \\
\hline \multirow[t]{2}{*}{ Non-Loser } & 0.265 & 0.654 & 0.081 \\
\hline & $(0.008)$ & $(0.009)$ & $(0.005)$ \\
\hline \multirow[t]{2}{*}{ F-T Job Loser } & 0.481 & 0.388 & 0.131 \\
\hline & $(0.040)$ & $(0.043)$ & $(0.025)$ \\
\hline \multirow[t]{2}{*}{ P-T Job Loser } & 0.217 & 0.711 & 0.072 \\
\hline & $(0.056)$ & $(0.060)$ & $(0.035)$ \\
\hline \multicolumn{4}{|l|}{ Invol P-T at DWS } \\
\hline \multirow[t]{2}{*}{ Non-Loser } & 0.558 & 0.208 & 0.234 \\
\hline & $(0.015)$ & $(0.012)$ & $(0.013)$ \\
\hline \multirow[t]{2}{*}{ F-T Job Loser } & 0.676 & 0.138 & 0.186 \\
\hline & $(0.046)$ & $(0.037)$ & $(0.039)$ \\
\hline \multirow[t]{2}{*}{ P-T Job Loser } & 0.540 & 0.170 & 0.290 \\
\hline & $(0.101)$ & $(0.082)$ & $(0.086)$ \\
\hline
\end{tabular}

Note to table 10: Based on tabulations from the Merged February 1994 and 1996 DWSs with the February 1995 and 1997 CAEASs respectively. Only those individuals employed at both dates are included in the analysis. See the text for a definitions of the job type classifications and for a description of the matching procedure. All fractions are weighted by CPS sampling weights from 1994 or 1996. The numbers in parentheses are standard errors. $n=30383$. 
TABLE 11: Part-Time Status by Employment Arrangement at CAEAS Date Merged Data

Workers aged 20-64 at DWS Date

(row fractions)

\begin{tabular}{|c|c|c|c|}
\hline Group & Full-Time & Vol P-T & Invol PT \\
\hline \multicolumn{4}{|l|}{ All Workers } \\
\hline \multirow[t]{2}{*}{ Regular } & 0.879 & 0.091 & 0.030 \\
\hline & $(0.002)$ & $(0.002)$ & $(0.001)$ \\
\hline \multirow[t]{2}{*}{ Contractor } & 0.745 & 0.153 & 0.101 \\
\hline & $(0.008)$ & $(0.007)$ & $(0.004)$ \\
\hline \multirow[t]{2}{*}{ Other-SE } & 0.784 & 0.154 & 0.062 \\
\hline & $(0.008)$ & $(0.007)$ & $(0.004)$ \\
\hline \multirow[t]{2}{*}{ Temporary } & 0.638 & 0.254 & 0.107 \\
\hline & $(0.008)$ & $(0.007)$ & $(0.005)$ \\
\hline \multicolumn{4}{|l|}{ Non-Losers } \\
\hline \multirow[t]{2}{*}{ Regular } & 0.880 & 0.091 & 0.029 \\
\hline & $(0.002)$ & $(0.002)$ & $(0.001)$ \\
\hline \multirow[t]{2}{*}{ Contractor } & 0.744 & 0.151 & 0.105 \\
\hline & $(0.008)$ & $(0.007)$ & $(0.004)$ \\
\hline \multirow[t]{2}{*}{ Other-SE } & 0.790 & 0.150 & 0.059 \\
\hline & $(0.008)$ & $(0.007)$ & $(0.005)$ \\
\hline \multirow[t]{2}{*}{ Temporary } & 0.616 & 0.277 & 0.108 \\
\hline & $(0.009)$ & $(0.008)$ & $(0.005)$ \\
\hline \multicolumn{4}{|c|}{ All Job Losers } \\
\hline \multirow[t]{2}{*}{ Regular } & 0.869 & 0.087 & 0.044 \\
\hline & $(0.007)$ & $(0.006)$ & $(0.005)$ \\
\hline \multirow[t]{2}{*}{ Contractor } & 0.754 & 0.179 & 0.066 \\
\hline & $(0.026)$ & $(0.022)$ & $(0.016)$ \\
\hline \multirow[t]{2}{*}{ Other-SE } & 0.651 & 0.232 & 0.117 \\
\hline & $(0.039)$ & $(0.032)$ & $(0.024)$ \\
\hline \multirow[t]{2}{*}{ Temporary } & 0.736 & 0.159 & 0.105 \\
\hline & $(0.020)$ & $(0.017)$ & $(0.013)$ \\
\hline \multicolumn{4}{|c|}{ F-T Job Losers } \\
\hline \multirow[t]{2}{*}{ Regular } & 0.911 & 0.052 & 0.037 \\
\hline & $(0.008)$ & $(0.006)$ & $(0.006)$ \\
\hline \multirow[t]{2}{*}{ Contractor } & 0.754 & 0.147 & 0.099 \\
\hline & $(0.031)$ & $(0.024)$ & $(0.021)$ \\
\hline \multirow[t]{2}{*}{ Other-SE } & 0.729 & 0.143 & 0.128 \\
\hline & $(0.047)$ & $(0.037)$ & $(0.033)$ \\
\hline \multirow[t]{2}{*}{ Temporary } & 0.768 & 0.109 & 0.124 \\
\hline & $(0.024)$ & $(0.019)$ & $(0.017)$ \\
\hline
\end{tabular}

Note to table 11: Based on tabulations from the Merged February 1994 and 1996 DWSs with the February 1995 and 1997 CAEASs respectively. Only those individuals employed at the CAEAS date are included in the analysis. See the text for a definitions of the job type classifications, and for a description of the matching procedure. All fractions are weighted by CPS sampling weights from 1994 or 1996 . The numbers in parentheses are standard errors. $\mathrm{n}=33296$. 